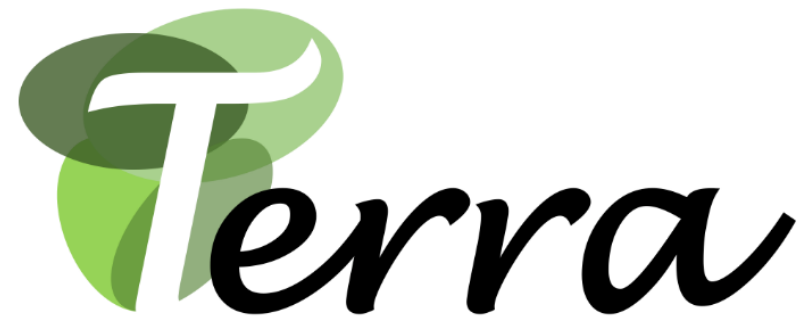

Revista de Desarrollo Local

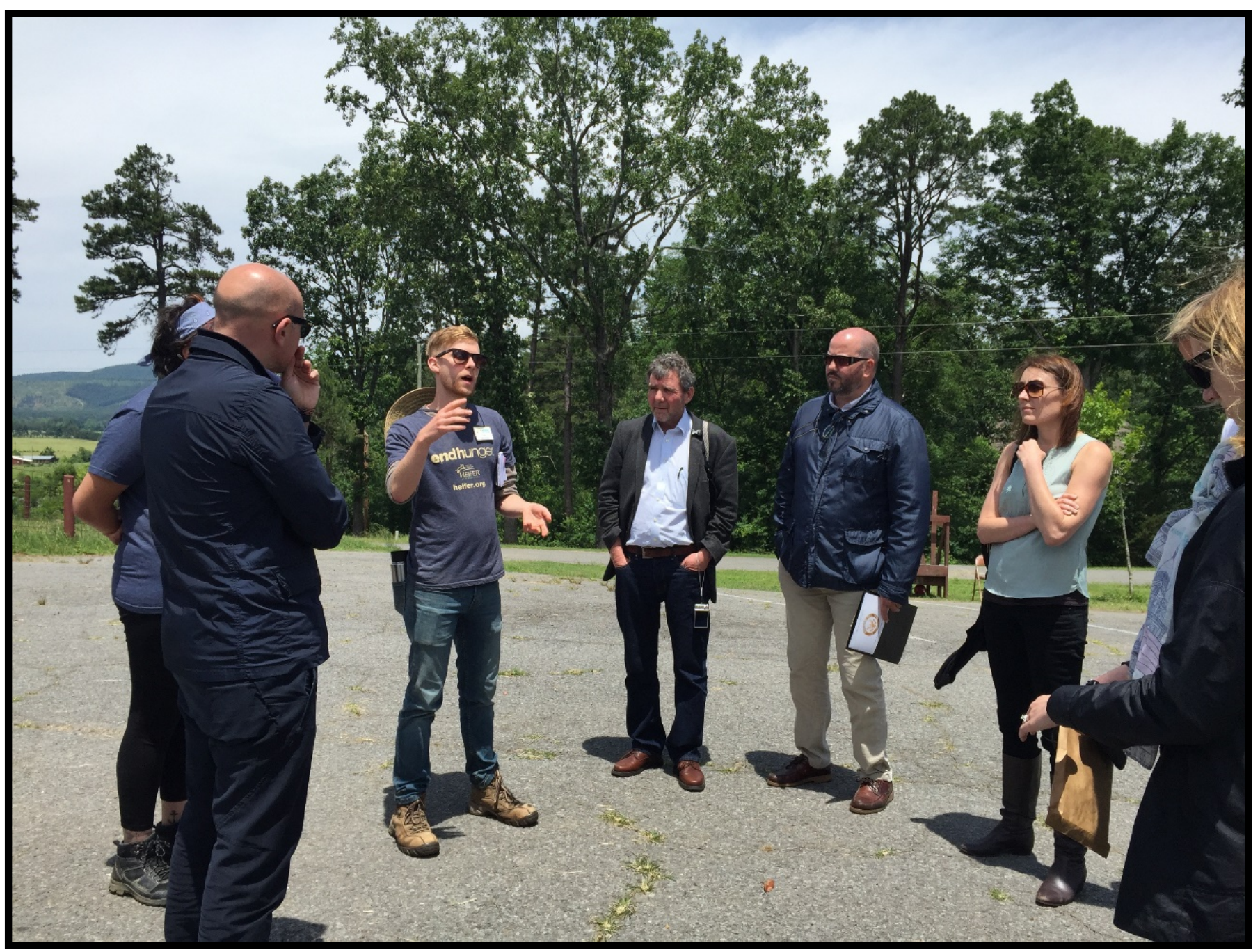

- Homenaje a Joan Noguera Tur -

\section{UI】! UNIVESSTAT}

Institut Interuniversitari

de Desenvolupament Loca
Iid1

\begin{tabular}{llllllll}
\hline & $N$ & $S$ & $T$ & I & $T$ & $U$ & $T$
\end{tabular}

INTERUNIVERSITARI DE

DESENVOLUPAMENI LOCAL

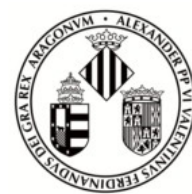

VNIVERSITAT

(E) ValènCia 
TERRA. Revista de Desarrollo Local e-ISSN: 2386-9968

Número 8 (2021), 253-279

DOI 10.7203/terra.8.20364

IIDL - Instituto Interuniversitario de Desarrollo Local

\title{
La adaptación al cambio climático, una oportunidad para el desarrollo territorial sostenible en escalas regional, subregional y local: ejemplos en el territorio valenciano
}

\author{
Jorge Olcina Cantos \\ Departamento de Análisis Geográfico Regional y Geografía Física (Universidad de \\ Alicante) \\ Jorge.olcina@ua.es \\ https://orcid.org/0000-0002-4846-8126
}

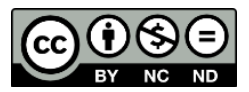

Esta obra se distribuye con la licencia Creative Commons

Reconocimiento-NoComercial-SinObraDerivada 4.0 Internacional 


\title{
SECCIÓN ARTÍCULOS
}

\section{La adaptación al cambio climático, una oportunidad para el desarrollo territorial sostenible en escalas regional, subregional y local: ejemplos en el territorio valenciano}

Resumen: Las acciones de adaptación al cambio climático van a marcar la agenda política en los próximos años y décadas. De hecho, ya se están desarrollando actuaciones concretas en las escalas regional y local en España. La Comunidad Valenciana ha puesto en marcha diversas acciones, de planificación y normativa que en los últimos años están teniendo repercusión en la escala local. Los municipios no siempre entienden los beneficios de una planificación territorial sostenible, debido a que no ha habido tradición en nuestro país de actuaciones de sostenibilidad territorial. Se estudia esta cuestión haciendo mención a los ejemplos de buenas prácticas internacionales y se analizan tres iniciativas que suponen un cambio en la cultura territorial en el ámbito valenciano, impulsadas por el gobierno regional y que van a tener efectos concretos en la escala local en el marco del proceso actual de adaptación al proceso de calentamiento climático.

Palabras clave: planificación territorial sostenible; cambio climático; adaptación; escalas regional, subregional y local.

\section{Adaptation to climate change, an opportunity for sustainable spatial planning at regional, subregional and local scales: examples in Valencian region}

\begin{abstract}
Actions to adapt to climate change will shape the political agenda in the coming years and decades. In fact, concrete actions are already being developed at the regional and local levels in Spain. Valencian Community has launched, in recent years, various actions, both planning and regulatory, that are having an impact on local scale. Municipalities do not always understand the benefits of sustainable territorial planning, because there has been no tradition in our country of territorial sustainability actions. This question is studied by mentioning the examples of international good practices and three initiatives that imply a change in the territorial culture in the Valencian territory, promoted by the regional government and that will have concrete effects on the local scale in the framework of the current process of adaptation to the global warming process.
\end{abstract}

Key words: sustainable spatial planning; climate change; adaptation; regional, subregional and local scales.

Recibido: 09 de noviembre de 2020

Devuelto para revisión: 23 de abril de 2021

Aceptado: 29 de abril de 2021

Referencia / Citation:

Olcina, J. (2021). La adaptación al cambio climático, una oportunidad para el desarrollo territorial sostenible en escalas regional, subregional y local: ejemplos en el territorio valenciano. TERRA. Revista de Desarrollo Local, (8), 253-279. DOI 10.7203/terra.8.20364 
IDEAS CLAVE / HIGHLIGHTS / IDEES CLAU

1. La ordenación del territorio debe considerar los recursos y los riesgos del medio como principios rectores de las actuaciones de planificación territorial.

2. Las escalas regional, subregional y local deben incorporar el cambio climático como elemento de la infraestructura verde a la hora de asignar nuevos usos del suelo.

3. Los aspectos que debe incorporar la infraestructura verde en la planificación territorial y urbana para reducir los efectos del calentamiento climático son: a) el aumento de temperaturas y pérdida del confort térmico, b) la subida del nivel del mar en áreas litorales, y c) los cambios en las precipitaciones.

4. En la Comunidad Valenciana se han desarrollado algunas acciones, planes y normas, que tienen el cambio climático como principio rector para la consecución de un desarrollo territorial sostenible: el PATIVEL, el Plan Vega Renhace y la Ley Valenciana de Cambio Climático.
1. Spatial planning must consider the resources and risks of the environment as guiding principles for spatial planning actions.

2. Regional, sub-regional and local scales should incorporate climate change as an element of green infrastructure when allocating new land uses.

3. The aspects that green infrastructure must incorporate into territorial and urban planning to reduce the effects of global warming are: a) the increase in temperatures and loss of thermal comfort, b) the rise in sea level in coastal areas, and c) changes in precipitation.

4. In the Valencian Community, some actions, plans and regulations have been developed that take climate change as a guiding principle for the achievement of sustainable territorial development: the PATIVEL, the Vega Renhace Plan and the Valencian Law on Climate Change.
1. L'ordenació del territori ha de considerar els recursos i els riscos del mitjà com a principis rectors de les actuacions de planificació territorial.

2. Les escales regional, subregional i local han d'incorporar el canvi climàtic com a element de la infraestructura verda a l'hora d'assignar nous usos del sòl

3. Els aspectes que ha d'incorporar la infraestructura verda en la planificació territorial i urbana per a reduir els efectes del calfament climàtic són: a) l'augment de temperatures i pèrdua del confort tèrmic, b) la pujada del nivell de la mar en àrees litorals, i c) els canvis en les precipitacions.

4. A la Comunitat Valenciana s'han desenvolupat algunes accions, plans i normes, que tenen el canvi climàtic com a principi rector per a la consecució d'un desenvolupament territorial sostenible: el PATIVEL, el Pla Vega Renhace i la Llei Valenciana de Canvi Climàtic. 


\section{INTRODUCCIÓN: CAMBIO CLIMÁTICO Y PLANIFICACIÓN TERRITORIAL}

El proceso de cambio climático actual es una evidencia científica con efectos directos en los elementos atmosféricos (temperatura, precipitaciones, etc.), pero con repercusiones también en los usos y actividades implantadas en el territorio (IPCC, 2014, 2018). De ahí que la consideración del proceso de calentamiento térmico que se registra en las últimas décadas debe ser integral, abordando políticas y prácticas que afecten a las causas y a los efectos previstos en la modelización (Olcina, 2020). Las escalas regional, subregional y local son decisivas en las actuaciones a desarrollar, al ser los ámbitos más próximos a la ciudadanía y los que tienen mayor capacidad para llevar a cabo las acciones de mayor impacto en la adaptación al cambio climático. Ello es así tanto por puesta en marcha de actuaciones propias, como por la aplicación de acciones derivadas de la aplicación, a nivel municipal, de las determinaciones de planes y normas de escala superior.

Si se entiende que la ordenación del territorio tiene como fines principales en toda sociedad democrática la de garantizar la participación de la población afectada; coordinar las distintas políticas sectoriales; respetar los valores, culturas e intereses de las diversas regiones o comarcas y, en particular, la de considerar la situación actual, la tendencia y la evolución a largo plazo de las políticas sobre el territorio, estamos ante una herramienta especialmente idónea para incorporar el cambio climático como un principio rector principal de actuaciones en la planificación de usos del suelo en la escala local (Elorrieta et al., 2016).

En la actualidad la ordenación del territorio tiene unos retos en el marco de la sostenibilidad y del cambio climático, como principio rector de las actuaciones a planificar en el medio: 1) debe considerar los recursos y los riesgos del medio físico; 2) debe incorporar las normativas ambientales emanadas por las administraciones competentes: 3 ) debe cumplir la jerarquía de las escalas de trabajo que son fundamentales en la práctica jurídica; y 4) debe incorporar una fase de diagnóstico continuado a partir del diseño de indicadores de seguimiento para la evaluación continua de los planes. Y todo ello bajo el principio de la transparencia y la información en abierto a la sociedad por parte de las administraciones competentes.

La necesidad de ir adaptando la ordenación territorial a la dinámica socio-económica y ambiental de los territorios, incluye, por tanto, la incorporación del proceso actual que, en mayor medida va a determinar la planificación territorial en los próximos años: el cambio climático. El calentamiento térmico y los efectos previstos en las temperaturas y precipitaciones en las diferentes regiones del mundo va a condicionar la planificación del territorio que debe convertirse en una herramienta eficaz de adaptación al cambio climático. La pérdida de confort térmico que se prevé en las próximas décadas puede encontrar en el diseño de edificios (arquitectura bioclimática) o de zonas verdes en las ciudades un elemento de reducción de su impacto. Por su parte, el aumento en las lluvias intensas y los procesos de inundación que se manifiesta ya en varias regiones del mundo debe mitigar sus efectos con propuestas de ordenación del territorio basadas en el uso de cartografías de riesgo y delimitación precisa de áreas donde no plantear usos intensivos del suelo por su elevada peligrosidad. Sin olvidar los efectos que el calentamiento climático está teniendo en zonas costeras por la subida del nivel del agua del mar y que va a condicionar actuaciones territoriales en las áreas litorales durante las próximas décadas (Olcina, 2013, 2020). 
La ordenación del territorio ha ido mejorando sus procedimientos y métodos de trabajo en las últimas décadas, en relación con la aparición de normas que han propiciado la consideración de los elementos naturales y culturales del medio como piezas importantes a considerar en la planificación de nuevos usos (Farinós, 2012). En muchos países del mundo occidental se ha pasado de concepciones básicamente económicas de la planificación territorial, que consideran el suelo como un espacio de posibilidades, de asignación directa de nuevos usos, a posiciones más racionales que valoran los recursos naturales y el patrimonio histórico-artístico como piezas principales de los territorios (Berezi y Olcina, 2021). A partir de una delimitación precisa y del establecimiento de medidas de protección es posible diseñar nuevos usos que sean compatibles con aquellos. En Europa la apuesta por la sostenibilidad territorial y la adaptación al cambio climático es un hecho plasmado recogido diferentes documentos estratégicos que van a marcar las políticas de planificación territorial y urbana de los países de la Unión en los próximos años -EU Strategy of Green Infraestructure, Agenda Urbana de la UE, Agenda Territorial, 2030 y European Green Deal- (Katuric, 2021)

La incorporación del paisaje, como criterio fundamental de planificación, y de la infraestructura verde como herramienta para la gestión territorial, permiten incorporar, entre otros aspectos, el cambio climático a la ordenación del territorio (Sánchez Cabrera, 2015). Para ello se han perfeccionado, en los últimos años, las cartografías y los modelos que se pueden utilizar a la hora de definir las capas de infraestructura verde que establecen la primera delimitación entre el área geográfica a proteger, con diferentes determinaciones, y el área geográfica que potencialmente puede actuarse (Meerow y Newell, 2017). Teniendo en cuenta que el clima actual y los efectos futuros sobre él del proceso de calentamiento térmico, tiene un comportamiento "normal" y otro "extremo". Y ambos son indisolubles en su incorporación en los documentos de ordenación territorial, en las escalas regional, subregional y local.

\section{LA INCORPORACIÓN DEL CAMBIO CLIMÁTICO A LA ORDENACIÓN DEL TERRITORIO}

La incorporación del cambio climático en los procesos de planificación del espacio requiere análisis precisos con finalidad aplicada para los fines que se persiguen en la asignación de nuevos usos en el suelo y de plasmación cartográfica que permita la delimitación de áreas más y menos aptas para la implantación de nuevas actividades. Los informes de aspectos del medio físico que se incorporaban hace unos años en los planes urbanísticos y que resultaban una copia sin sentido de tratados o manuales de geografía existentes en el ámbito objeto de planificación no tienen sentido en la actualidad. Ni lo tenían entonces. Pero la no incorporación de profesionales conocedores del tratamiento racional del medio físico en los equipos de elaboración de estos documentos originaba estos desajustes territoriales que han derivado, en muchos casos, en creación de "territorios de riesgo". Esta situación ha ido mejorando en los últimos años, al reconocerse la valía profesional de la geografía, y de otras ciencias ambientales, en las labores de planificación territorial.

En la actualidad no se entiende la confección de un PGOU o de un plan territorial de escala más amplia, si un informe del medio natural detallado, completo y con cartografía precisa. Por otro lado, es un aspecto al que ha ido obligando, afortunadamente, la legislación con incidencia en la ordenación del territorio que se ha ido aprobando en las 
escalas estatal y regional (suelo, ordenación del territorio, impacto ambiental, agua, paisaje, etc.).

El desarrollo reciente, sin desconocer sus antecedentes, de la herramienta de planificación de la infraestructura verde está permitiendo racionalizar los procesos de ordenación territorial, al permitir la incorporación de nuevas "capas" en los sistemas de información territorial que determinan la clasificación primera del suelo a actuar (Vera-Rebollo et al., 2019). La infraestructura verde se maneja en un doble sentido, complementario, como herramienta para la ordenación sostenible de los territorios: como conjunto de infraestructuras urbanas diseñadas bajo criterios de sostenibilidad para la evacuación de aguas pluviales y como herramienta cartográfica para la planificación territorial sostenible (Breuste et al., 2015). En este último sentido, varias ciudades del mundo han diseñado sistemas sostenibles para la circulación de aguas pluviales (SDUS), a partir de la construcción de colectores de gran capacidad, de instalación de tanques de tormenta $\mathrm{o}$ diseño de parques inundables para reducir la peligrosidad de inundaciones urbanas.

Figura 1. Aspectos del cambio climático y de los riesgos climáticos que pueden incorporarse a la infraestructura verde y la planificación territorial

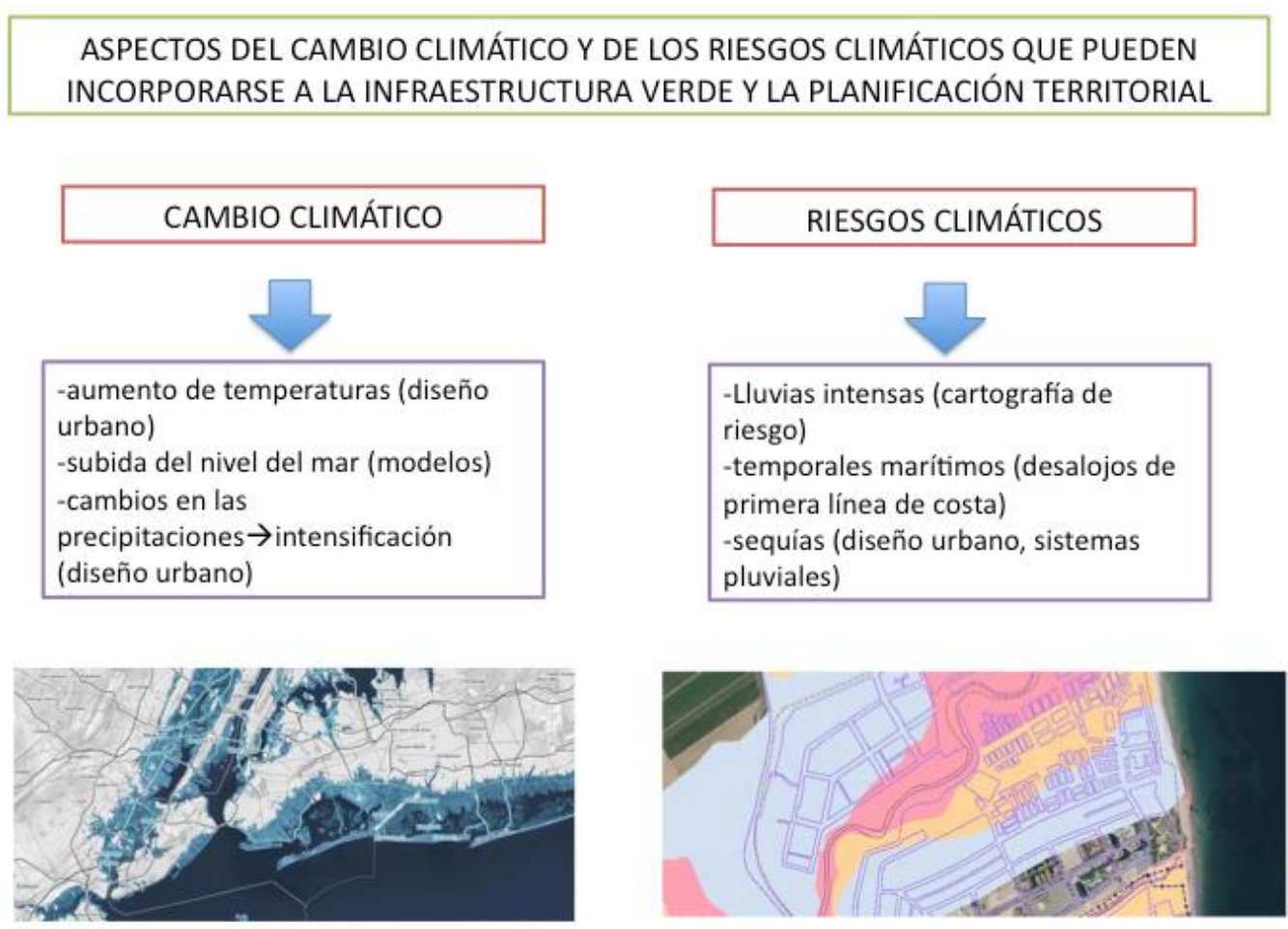

Elaboración propia. Mapas tomados de: New York $2^{\circ} \mathrm{C}$ warning and sea level rise. Disponible en: https://ss6m.climatecentral.org/\#11/40.6643/-73.9385; y Plan Acción Territorial frente al Riesgo de Inundaciones de la Comunidad Valenciana (PATRICOVA).

Por su parte, comienzan a incorporarse elementos para la gestión del riesgo y del cambio climático en los procesos de planificación territorial a partir del empleo de la infraestructura verde. Los aspectos que de forma específica debe incorporar la infraestructura verde en la planificación urbana y territorial para reducir los efectos del calentamiento climático son los siguientes: a) aumento de temperaturas y pérdida del confort térmico, cuyos efectos pueden mitigarse a partir de medidas de diseño urbano como el aumento de parques públicos, de espacios verdes en viviendas (terrazas y 
fachadas verdes): b) subida del nivel del mar en áreas litorales, cuyos efectos deben reducirse con acciones estructurales, en algunos casos, y con planificación territorial (regulación de usos en la línea costera, desocupación de primeras líneas de costa). Y c) cambios en las precipitaciones, con incremento de su intensidad y de su irregularidad, lo que obliga a diseñar espacios para el drenaje de aguas de gran capacidad, así como depósitos de almacenamiento de agua de mayor capacidad que los existentes para garantizar el abastecimiento de las demandas urbanas.

Todo ello debe basarse en la elaboración de modelos de comportamiento de los elementos climáticos o ambientales (nivel del mar) rigurosos y que permitan la actualización periódica de las proyecciones de cara a su aplicación en la planificación territorial (Figura 1).

Un elemento fundamental para incorporar el cambio climático y los riesgos asociados en los procesos de planificación territorial es el mapa (Olcina, 2020). En efecto, la infraestructura verde debe contener cartografía de detalle escalar. En muchos países, el mapa se ha convertido en el documento de acreditación legal de la condición de riesgo de un territorio objeto de planificación. Un mapa de riesgo de inundación es un documento clave para la clasificación urbanística, de ahí que su elaboración requiera precisión y detalle. No es un mapa de peligrosidad, como ha sido habitual elaborar en los análisis del riesgo con finalidad urbanística; el mapa de riesgo incluye peligrosidad y agrega la vulnerabilidad social, económica y patrimonial. La escala de elaboración debe adaptarse a las tramas urbanas y para ello es necesario, además de ajustes cartográficos, la realización de trabajo de campo para confirmar los resultados que ofrecen los portales cartográficos de las administraciones (Olcina y Díez, 2016). Las administraciones competentes en materia urbanística deben velar porque los mapas de riesgo natural que acompañen los documentos de planeamiento urbanístico estén elaborados con los criterios de rigor y en la escala idónea para el espacio geográfico objeto de transformación.

El presente trabajo indaga en el proceso de incorporación del cambio climático y sus manifestaciones atmosféricas extremas asociadas al mismo en la ordenación territorial, a partir del análisis de propuestas concretas de planificación o de orientación normativa con efectos de la futura asignación de usos del suelo en la Comunidad Valenciana. La apuesta por la sostenibilidad que ha emprendido esta región en los últimos años en el desarrollo de la legislación y planes de ordenación territorial está generando documentos de interés que pueden ser tenidos como ejemplo de buenas prácticas de orientación para otros espacios regionales españoles. El análisis crítico de planes y normas tiene por objeto proponer orientaciones para su implementación futura.

\section{MÉTODO}

El análisis de la incorporación del cambio climático y sus extremos atmosféricos asociados a la planificación territorial que se aborda en el presente estudio está basado en las siguientes fases:

a) Consulta bibliográfica, para el estudio de experiencias internacionales y españolas de incorporación del cambio climático a la ordenación territorial.

b) Revisión de planes y normas relacionadas con la ordenación territorial y cambio climático en la Comunidad Valenciana, que ha iniciado en los últimos años un proceso 
decidido de planificación de usos del suelo orientado bajo los principios de la sostenibilidad y atendiendo a la necesidad de adaptación al cambio climático (Tabla 1).

c) Análisis crítico de la situación de los planes y norma seleccionados para su estudio en el presente trabajo, con objeto de elaborar propuestas a llevar a cabo por parte de las administraciones que deben gestionar su aplicación para su completo desarrollo.

Tabla 1. Planes y norma analizados en el presente trabajo

\begin{tabular}{|c|c|c|}
\hline PLAN O LEY & CARÁCTER & Ã̃O \\
\hline $\begin{array}{l}\text { PATIVEL (Plan de Acción Territorial de } \\
\text { Infraestructura Verde del Litoral Valenciano)* }\end{array}$ & Normativo & 2017 \\
\hline $\begin{array}{l}\text { PLAN VEGA RENHACE (Plan para la } \\
\text { Resiliencia de la Vega Baja del Segura) }\end{array}$ & Estratégico & 2020 \\
\hline $\begin{array}{l}\text { LEY VALENCIANA DE CAMBIO } \\
\text { CLIMÁTICO Y TRANSICIÓN ECOLÓGICA }\end{array}$ & Normativo & $\begin{array}{c}2020 \\
\text { (Anteproyecto de ley) }\end{array}$ \\
\hline
\end{tabular}

Fuente: elaboración propia. *El PATIVEL ha sido declarado nulo por sentencia del Tribunal Superior de Justicia de la Comunidad Valenciana, de 11 de febrero de 2021. La Generalitat Valenciana ha interpuesto recurso al Tribunal Supremo. Está pendiente de sentencia (vid. apartado 4.1).

La incorporación del cambio climático en los procesos de ordenación territorial es un proceso nuevo que se está desarrollando en diversos países y regiones del mundo y que muestra lentitud de actuación en el caso español. De ahí la necesidad de analizar ejemplos que se están poniendo en marcha en los últimos años y que pueden servir de buenas prácticas para su aplicación en las escalas regional y local. Además, en los casos analizados se ha manejado la infraestructura verde como herramienta de planificación, a la que se ha incorporado información (capas) sobre modelización climática con incidencia en la asignación futura de usos del suelo, como se señala a continuación.

\section{RESULTADOS. PLANES Y NORMATIVAS PARA LA ADAPTACIÓN DEL TERRITORIO AL CAMBIO CLIMÁTICO: EJEMPLOS EN LA COMUNIDAD VALENCIANA}

La Comunidad Valenciana es un buen ejemplo de contradicción en el conjunto de regiones españolas en materia de ordenación territorial, que se manifiesta en las diferencias notables entre las formulaciones teóricas (estrategias y planes) y la realidad urbanística vivida durante las últimas décadas. A partir de la crisis desencadenada en 2008 la administración regional aprueba un nuevo marco de planificación territorial (Gaja Díaz, 2008; Burriel de Orueta, 2008 y 2009) que cuestiona en buena medida los principios rectores del anterior modelo de crecimiento urbanístico expansivo y sin apenas límites en el territorio, manejado básicamente desde la escala local (Capdepón, 2016).

$\mathrm{Su}$ franja litoral, que reúne unas condiciones ambientales favorables, es, sin duda, el espacio de conflicto en materia de planificación territorial y urbanística, al concentrar el porcentaje mayor de población y de actividades económicas, en particular el turismo de sol y playa, motor económico esencial de la economía valenciana (Ariño y García, 2018). No es de extrañar, de este modo, que la Comunidad Valenciana encabece la lista de regiones españolas de agresiones al espacio litoral, lo que manifiesta la necesidad de una 
protección efectiva de la franja litoral y de una gestión real del territorio. Así, entre los efectos ambientales más notables aparece la degradación de los recursos hídricos y de los ecosistemas acuáticos, que está en contradicción con la apuesta por la sostenibilidad del territorio que demandan tanto los residentes como los turistas (Tudela y Delgado, 2018).

La Comunitat Valenciana inició una nueva etapa en los procesos de ordenación territorial de escala regional y subregional en 2011, con la aprobación de la Estrategia Territorial de la Comunitat Valenciana (Decreto 1/2011, de 13 de enero). En este documento se manifestaba, de forma explícita, la apuesta por una planificación sostenible del espacio geográfico, siguiendo los principios establecidos por la Estrategia Territorial Europea (1999). A ello se sumó la apuesta decidida, en el ámbito europeo, por la gestión del paisaje como herramienta de ordenación del territorio. La Comunidad Valenciana, junto a Cataluña, fue una de las regiones españolas que más temprano aprobó una normativa de planificación territorial que incorporaba la obligación de considerar el paisaje en los procesos de ordenación territorial (Ley valenciana de Ordenación del Territorio y Paisaje, Ley 4/2004). Con este marco normativo, -revisado y actualizado en 2014 (Ley 5/2014, de 25 de julio)-, se elaboró y aprobó la Estrategia Territorial de la Comunitat Valenciana que supuso una apuesta decidida por la sostenibilidad del territorio, empleando el paisaje como una herramienta de gestión fundamental. La obligación establecida en este texto legal, de elaborar una cartografía precisa de unidades paisajísticas previa a la clasificación urbanística del suelo, abrió un proceso de planificación territorial de enorme interés y sin vuelta atrás (Padilla et al., 2019).

La derogada Ley 4/2004, de Ordenación del Territorio y protección del Paisaje modificada por la Ley 1/2019-, estableció la elaboración de la Estrategia Territorial de la Comunitat Valenciana (ETCV), como instrumento de ordenación territorial de escala regional. Debe destacarse, por tanto, que la Comunitat Valenciana ha sido un territorio sin proyecto desde la creación de la propia Autonomía (Estatuto de Autonomía de 1982, rev. 2006) hasta 2011 debido a la inexistencia de un plan o directrices de escala regional. Es cierto que en 1995 la Conselleria de Obras Públicas, Urbanismo y Transportes elaboró el documento "Estrategias de Vertebración Territorial" (Colección Territori, $\mathrm{n}^{\mathrm{o}} 5$ ) con directrices claras en cuanto a la planificación a escala regional, aunque no se desarrollaron como texto normativo. Este hecho explica, asimismo, la enorme transformación del territorio vivida en esta región en las tres últimas décadas, originada por la aprobación de planes urbanísticos de escala municipal claramente expansionistas y con poco margen de limitación, por inexistencia de planes regionales o subregionales de ordenación del territorio contemplados en las diferentes normativas de ordenación del territorio aprobadas en todos esos años.

Junto al paisaje, el otro gran componente de la ordenación del territorio establecido por la Ley de Ordenación territorial de la Comunidad Valenciana es la infraestructura verde. En efecto, la actual Ley de Ordenación del Territorio, Urbanismo y Paisaje (DOCV 7.329, 2017; BOE 231, 2014) incluye en su exposición de motivos, su apuesta decidida por este concepto: "La definición de la Infraestructura Verde debe ser previa a la planificación de las nuevas demandas de suelo y debe abarcar todas las escalas del territorio..." y dedica un título específico a la infraestructura verde, como método de trabajo en la planificación territorial, a diferente escala (regional, supramunicipal, municipal y urbana), de obligada observancia con carácter previo a la ordenación de usos y actividades en el territorio.

La Estrategia Territorial de la Comunidad Valenciana (2011) señala que uno de los objetivos principales de la política de paisaje es definir la infraestructura verde, a modo de una red interconectada conformada por los paisajes de mayor valor medioambiental, 
cultural y visual que se convertirá en la estructura básica ecológica. En ella se define la infraestructura verde como una "herramienta clave de planificación territorial que debe orientar los crecimientos urbanísticos del futuro preservando el territorio de mayor valor que debe quedar fuera de este proceso urbanizador". Además, condiciona los futuros crecimientos de suelo con la capacidad de acogida del territorio, que debe ser definida por la infraestructura verde como fase previa a cualquier desarrollo urbanístico o territorial.

\subsection{PATIVEL, última oportunidad para proteger las últimas "ventanas" libres del litoral valenciano}

La plasmación concreta del uso de la infraestructura verde como herramienta principal de la ordenación del territorio en la Comunidad Valenciana ha venido de la mano de la redacción y aprobación del PATIVEL (Plan de Acción Territorial de Infraestructura Verde del Litoral de la Comunidad Valenciana). Ha sido una apuesta del gobierno valenciano porque afecta al espacio geográfico de mayor deseo de transformación para uso urbano y con mayor valor económico.

Debe recordarse, como antecedente de este plan, que, en 2002, el gobierno autonómico presentó una "Estrategia Valenciana para la Gestión Integrada de la Costa" (EVGIZC), que se apuntaba como la "base de la política de la Generalitat Valenciana en este campo". Sin embargo, no tuvo el desarrollo posterior esperado y, en conjunto, se puede afirmar que la región no ha contado con una política de gobierno especifica en materia de gestión integrada de áreas litorales, por lo menos de manera explícita. Realmente, este documento no era una estrategia propiamente dicha sino un trabajo previo que debería haber servido para un debate social e institucional. Eso sí, reconocía los principales problemas existentes en el litoral valenciano y la relevancia de la Gestión Integrada de Áreas Litorales (GIAL) para su solución, pese a que hace hincapié explícitamente en su carácter sectorial, como política territorial. Tras su publicación, no tuvo mayor repercusión en la política territorial valenciana, ni sirvió como referencia en organismos o administraciones con competencias en el litoral o incluso en los propios municipios litorales a la hora de revisar su planeamiento urbanístico.

No ha sido, por tanto, hasta la aprobación del PATIVEL (2018) cuando la Comunidad Valenciana ha aprobado un texto normativo que avala la gestión integrada del litoral, sumándose así a las iniciativas desarrolladas en otros territorios litorales de nuestro país. Incluso se ha ido más allá al apostar por la protección del paisaje y la definición precisa de la infraestructura verde para este espacio geográfico singular y complejo (VeraRebollo, Olcina y Sainz-Pardo, 2019). El PATIVEL se integra, por tanto, en la filosofía y procedimiento de ordenación territorial fijado en la legislación vigente en materia territorial y en los principios establecidos en la Estrategia Territorial Valenciana, donde el paisaje y la infraestructura verde forman los principios rectores orientadores de la planificación territorial en la Comunidad Valenciana. El PATIVEL es un instrumento de ordenación del territorio de ámbito supramunicipal diseñado desde la urgencia y el pragmatismo para tratar de conseguir la rápida protección de determinados suelos de clara apetencia económica, mediante la aplicación de los principios y filosofía que propone la ordenación de la infraestructura verde.

El PATIVEL persigue la definición y ordenación de la infraestructura verde supramunicipal del litoral, protegiendo sus valores ambientales, territoriales, paisajísticos, culturales, educativos y de protección frente a riesgos naturales e inducidos, así como garantizar la conectividad ecológica y funcional entre los espacios del litoral y 
los del interior y evitar la fragmentación de las piezas que forman la infraestructura verde. Las áreas de protección seleccionadas pretenden evitar la consolidación de continuos edificados y de barreras urbanas; esto es, se intenta conservar las últimas ventanas de suelo potencialmente urbanizable que están sin urbanizar en la costa valenciana. Y ello bajo una doble finalidad: la protección y conservación de paisajes y entornos naturales, pero también la utilización de esta protección como oferta turística de calidad.

Acorde con los principios de "ordenación integrada" del espacio litoral y no solo de la estricta franja costera, este plan afecta a 3 ámbitos definidos a partir de su distancia, tierra adentro, de la línea de costa:

a) Ámbito estricto, que comprende los suelos de los municipios litorales situados en la franja de 500 metros de amplitud medida en proyección horizontal tierra adentro desde el límite interior de la ribera del mar y coincidente con el área de influencia de la legislación de costas.

b) Ámbito ampliado, hasta los 1.000 metros de amplitud medida en proyección horizontal tierra adentro desde el límite interior de la ribera del mar, que dota de refuerzo y continuidad ecológica, funcional y visual a los suelos definidos en el apartado anterior y garantiza la amortiguación de los impactos sobre los mismos.

c) Ámbito de conexión, hasta los 2.000 metros de amplitud medida en proyección horizontal tierra adentro desde el límite interior de la ribera del mar, donde se analizará, ordenará y garantizará la conectividad ecológica y funcional del espacio litoral con el resto del territorio (Generalitat Valenciana, 2018).

En el PATIVEL se han aplicado los componentes de la infraestructura verde definidos inicialmente en la Estrategia Territorial de la Comunidad Valenciana (Ley 5/2014, mod. Ley $1 / 2019$, art. 5), que se estructura en una serie de componentes principales que forman los "pilares básicos" (en esencia, los espacios naturales con protección), unos servicios ambientales (forestales y agrícolas), unos espacios de especial atención (contaminación, riesgos), unos conectores y una infraestructura verde de escala urbana (parque, paseos, plazas).

No obstante, se han incorporado, algunos nuevos, como criterio para la delimitación de los ámbitos de protección, los siguientes:

- Los espacios de la zona marina.

- Los espacios costeros de interés ambiental y cultural.

- Las áreas de influencia del cambio climático en la franja litoral (subida del nivel del mar, áreas de inundación por incremento de episodios de crecida fluvial).

En este último aspecto, el PATIVEL resulta novedoso a escala estatal. Para ello ha tenido en cuenta el Informe de efectos del cambio climático en la costa española, avalado por el Ministerio de Transición Ecológica (Losada et al., 2014), así como otros trabajos sobre la costa valenciana para estimar la evolución de la costa valenciana en un doble sentido: erosión por deriva litoral (Figura 2) y efectos de temporales marítimos. Se ha preparado, además, una cartografía de detalle de los espacios costeros situados a cota inferior de un metro sobre el nivel del mar, para determinar áreas conflictivas por subida prevista del nivel del mar en la costa valenciana en el señalado informe del Ministerio de Transición Ecológica. 
Figura 2. Mapa de efectos en la costa valenciana, incorporado como criterio a la infraestructura verde en el PATIVEL

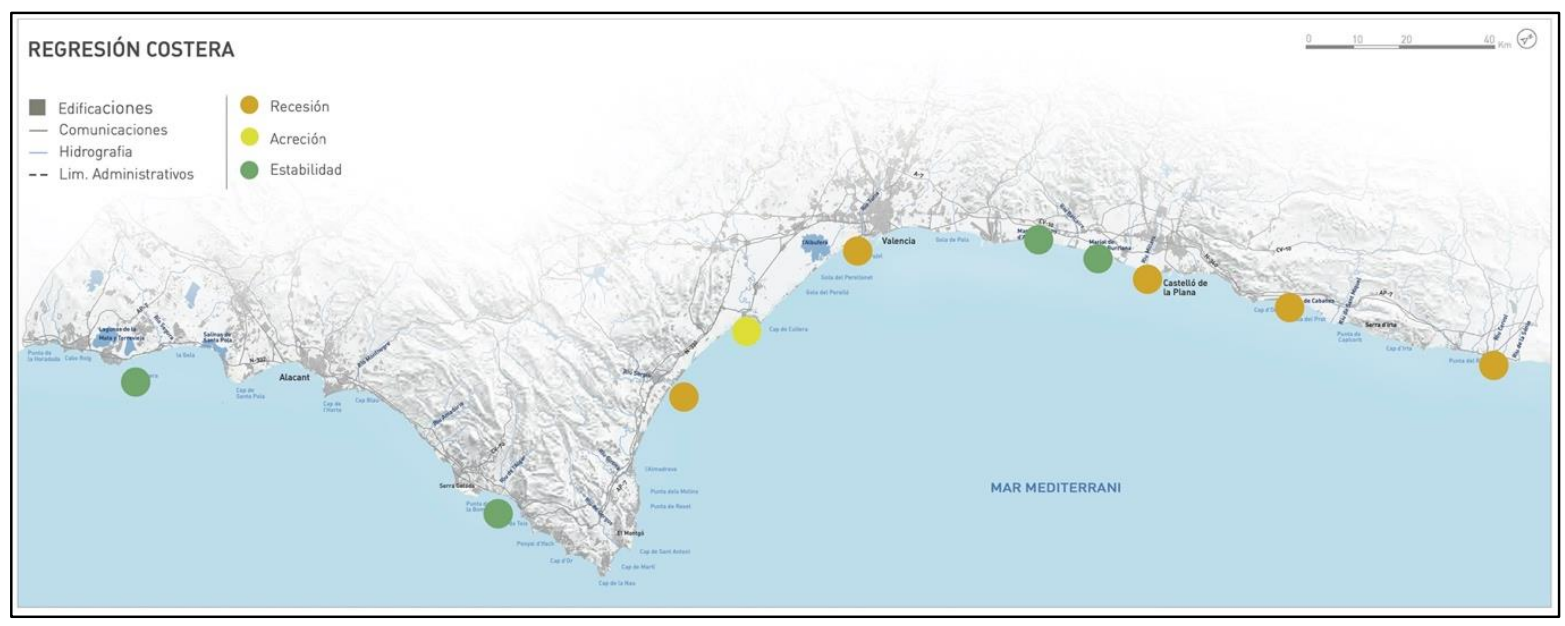

Fuente: PATIVEL, Generalitat Valenciana (2018).

Como acción concreta, de importancia normativa, el PATIVEL ha delimitado 52 áreas que deben preservarse libres de edificación, como piezas clave de la infraestructura verde del litoral (Conselleria de Vivienda, 2018) y que suponen, además de la protección de áreas que ya estaban declaradas como suelo no urbanizable, la desclasificación urbanística de 1.426 has de suelo en la franja litoral. Es decir, de suelos que podrían haberse urbanizado (Vera-Rebollo y Olcina, 2017). En su conjunto, el PATIVEL prevé la protección de un total de 7.500 ha. del litoral de la región, cifra que integra el $12 \%$ de los suelos que aún no han sido urbanizados en la franja de $500 \mathrm{mts}$. desde el límite interior de la ribera del mar. Como novedad en la política de valorización del litoral, el PATIVEL incluye un catálogo de playas, basado en la diferenciación entre playas urbanas y naturales con su correspondiente normativa de usos y ocupaciones, e incorpora la delimitación y trazado de la Vía del Litoral de la Comunitat Valenciana, definida como un eje estructural que articule los núcleos costeros y que formará parte de la infraestructura verde del litoral.

La declaración de la protección de las áreas incluidas en el PATIVEL por sí sola no garantiza su buena conservación. La viabilidad de crear una efectiva infraestructura verde en el litoral de la Comunitat Valenciana pasa por tener en cuenta la necesidad de gestionar el territorio a diversas escalas de manera coherente e interrelacionada (Padilla et. al., 2019). Se deben incorporar propuestas para la gestión de estos suelos que quedan protegidos. Para evitar que estas áreas sustraídas a la presión urbanizadora terminen abandonadas y siendo, como ya sucede en algunas de ellas, vertederos ilegales de enseres, es preciso que se afronten medidas, de manera conjunta entre la administración regional y local, que permitan una gestión eficaz de los espacios protegidos, así como el desarrollo de convenios con los propietarios del suelo; o, también, el desarrollo de fórmulas de custodia del territorio. La administración debe activar programas de paisaje en las áreas protegidas por el PATIVEL para que formen parte, en condiciones, de la infraestructura verde del litoral como espacios de valor ambiental, patrimonial y de valorización de la actividad turística. Otro aspecto sobre el que la administración debe estar vigilante es el posible incremento del precio del suelo y de las viviendas existentes en el entorno del área protegida que acabarían beneficiando a propietarios particulares sin que esas plusvalías reviertan en la comunidad local (Vera-Rebollo, Olcina y Sainz-Pardo, 2019). 
Como síntesis de la aprobación y puesta en marcha del PATIVEL se debe señalar que en su proceso de desarrollo se han presentado 4.615 recursos de propietarios afectados, ayuntamientos y colectivos profesionales ${ }^{1}$ en áreas especialmente conflictivas como Alcalá de Xivert, Oliva, Benissa y La Marina-Elx; por su parte, no se han desarrollado aún planes de gestión ni tampoco la propuesta de vía verde litoral contemplada en este texto normativo.

Con fecha 11 de febrero de 2021, el Tribunal Superior de Justicia de la Comunidad Valenciana ha declarado nulo el Plan de Acción Territorial de Infraestructura Verde del PATIVEL, atendiendo, en sentencia promulgada por dicha instancia judicial, al recurso planteado por una empresa de promoción urbanística. Los argumentos incluidos en la sentencia no afectan a los aspectos básicos del plan (criterios, método), pero indica fallos en la tramitación por carencia de informes necesarios (igualdad de género, estudio de alternativas, lucro cesante en zonas afectadas por la protección). La Consellería de Política Territorial, Obras Púbicas y Movilidad del Gobierno Valenciano ha interpuesto recurso de casación. Diversos colectivos y asociaciones han expresado su rechazo a esta sentencia contraria a los principios de desarrollo territorial sostenible y adaptación al cambio climático de la ordenación del territorio ${ }^{2}$.

\subsection{Plan Vega Renhace. Una apuesta para la resiliencia de un espacio geográfico de riesgo}

La comarca de la Vega Baja del Segura engloba territorios diversos, con marcados contrastes entre huerta, campo, costa y montaña, profundamente antropizados desde época histórica, caracterizados geográficamente por la presencia del río Segura en su tramo bajo, que ha sido fuente de riqueza y, en ocasiones, también de desastres. El Segura es el elemento que da sentido a la comarca. Un río de comportamiento mediterráneo desde su tramo medio hasta la desembocadura, con un caudal generalmente escaso que, sin embargo, experimenta crecidas desaforadas con ocasión de las lluvias torrenciales que se producen en el Sureste peninsular. La adversidad ha sabido convertirse en oportunidad casi siempre con medios propios, con el propio esfuerzo de los habitantes de la Comarca. Pero en ocasiones ha sido necesaria la ayuda externa en forma de inversiones, planes y actuaciones que permitieran recuperar la normalidad.

Las lluvias registradas durante los días 11 a 13 de septiembre de 2019 en algunas poblaciones de la Vega Baja del Segura no se habían registrado con tan elevadas intensidad y cuantía desde que hay registros meteorológicos. La Agencia Estatal de Meteorología calificó a esta "gota fría" o "DANA" (depresión aislada en niveles altos), como un "temporal de lluvias sin precedentes en los últimos 100 años en la zona. La localidad de Orihuela acumuló 521,6 mm de precipitación en los días del temporal, especialmente en la jornada del 12 de septiembre. Por su parte, el Centro Europeo de Predicción Meteorológica a Medio Plazo (ECMWF), en su informe anual (2019) incluyó el episodio de DANA de septiembre de 2019 en la Comunitat Valenciana y, en particular,

\footnotetext{
${ }^{1}$ Vid. documento elaborado al respecto por la Consellería de Habitatge, Obres Publiques y Vertebració del Territori de la Generalitat Valencianar Recuperado de http://politicaterritorial.gva.es/documents/20551069/162407502/Análisis+de+las+alegaciones+e+informe s+realizados+al+PATIVEL/adf16e3f-11cf-405c-bfb9-4241413a7881. Consultado: octubre 2019.

${ }^{2}$ Vid. al respecto, el documento "Valoración de la Delegación Territorial de la Comunitat Valenciana del Colegio de Geógrafos, con motivo de la sentencia del Tribunal Superior de Justicia de la Comunidad Valenciana, que anula el Plan de Acción Territorial de Infraestructura Verde del Litoral (PATIVEL)". Recuperado de https://www.age-geografia.es/site/wp-content/uploads/2021/04/VALORACIONCOLEGIO-DE-GEOGRAFOS-PATIVEL.pdf
} 
en la Vega Baja, como uno de los diez eventos atmosféricos extremos más destacados de este año.

La inundación de septiembre de 2019 evidenció la necesidad de preparar a la comarca de la Vega Baja, uno de los territorios con mayor grado de riesgo natural de la Comunitat Valenciana, para que su población y economía puedan resistir de mejor forma los efectos de futuros de episodios similares que puedan ocurrir. Unos extremos atmosféricos que, como señala la modelización climática, pueden ocurrir con mayor frecuencia en las próximas décadas.

La Vega Baja del Segura es una comarca con personalidad propia que ha sabido, por tanto, adaptarse a los peligros que, en ocasiones, manifiesta la naturaleza. Es una comarca "resistente" a la peligrosidad natural, no sin consecuencias a veces dramáticas. Porque en este territorio se producen excesos y escasez de agua, terremotos y temporales en la línea de costa. Estamos ante uno de los territorios de la Comunidad Valenciana más expuesto a una variedad amplia de peligros naturales.

Pero debe convertirse en una comarca "resiliente". En el contexto actual de calentamiento climático los eventos atmosféricos de efectos extremos se presumen más frecuentes, como indica la modelización climática en el litoral mediterráneo español (AEMET, 2019; Cramer et al., 2018). Y ello obliga a estar preparados, a adelantarse a los acontecimientos, a que los territorios diseñen programas y actuaciones que preparen a las sociedades que viven en ellos ante los cambios atmosféricos que se prevén y que pueden tener efecto en las actividades económicas y la vida social en su conjunto.

Un territorio "resiliente" es aquel que es capaz de recuperarse de forma rápida y aprovechando básicamente sus propios recursos humanos y económicos a los efectos catastróficos causados por el evento extremo, de causa natural o humana. En la Vega Baja del Segura se han llevado a cabo en las últimas décadas acciones de planificación con objeto de mejorar la resiliencia de la comarca ante los peligros naturales que han tenido un carácter "sectorial", esto es, han estado orientadas a disminuir el riesgo de un peligro natural específico (inundaciones, sequías, sismicidad). Pero no se ha desarrollado una planificación "integral" que aúne actuaciones orientadas a mejorar la resiliencia de la comarca en relación con la diversidad de peligros naturales que pueden afectar a los diferentes sectores económicos y a los núcleos de población, de forma conjunta.

La finalidad última del Plan Vega Renhace (Generalitat Valenciana, 2020) es convertir la catástrofe en una ocasión para impulsar un entorno resiliente que favorezca la regeneración económica y social de la Vega Baja. Y, al tiempo, promover un desarrollo territorial, absolutamente respetuoso con el medio ambiente, que prepare para futuros episodios de temporales, y que posibilite una mayor vertebración del territorio de la Vega Baja con el resto de la Comunitat Valenciana. El Plan Vega Renhace se ha organizado en cuatro Pilares fundamentales: coordinación, consenso, evidencia y resiliencia. Pilares que han actuado de hilo vertebrador de la necesidad de aunar esfuerzos de diversos actores, públicos y privados, para la consecución de grandes objetivos comunes (Figura 3).

El consenso es fundamental porque una iniciativa de estas características debe contar con el apoyo de todas las administraciones, pero también de todos los actores sociales y en particular de los residentes en la comarca. 
Figura 3.-Ejes estratégicos y pilares conceptuales del Plan Vega Renhace

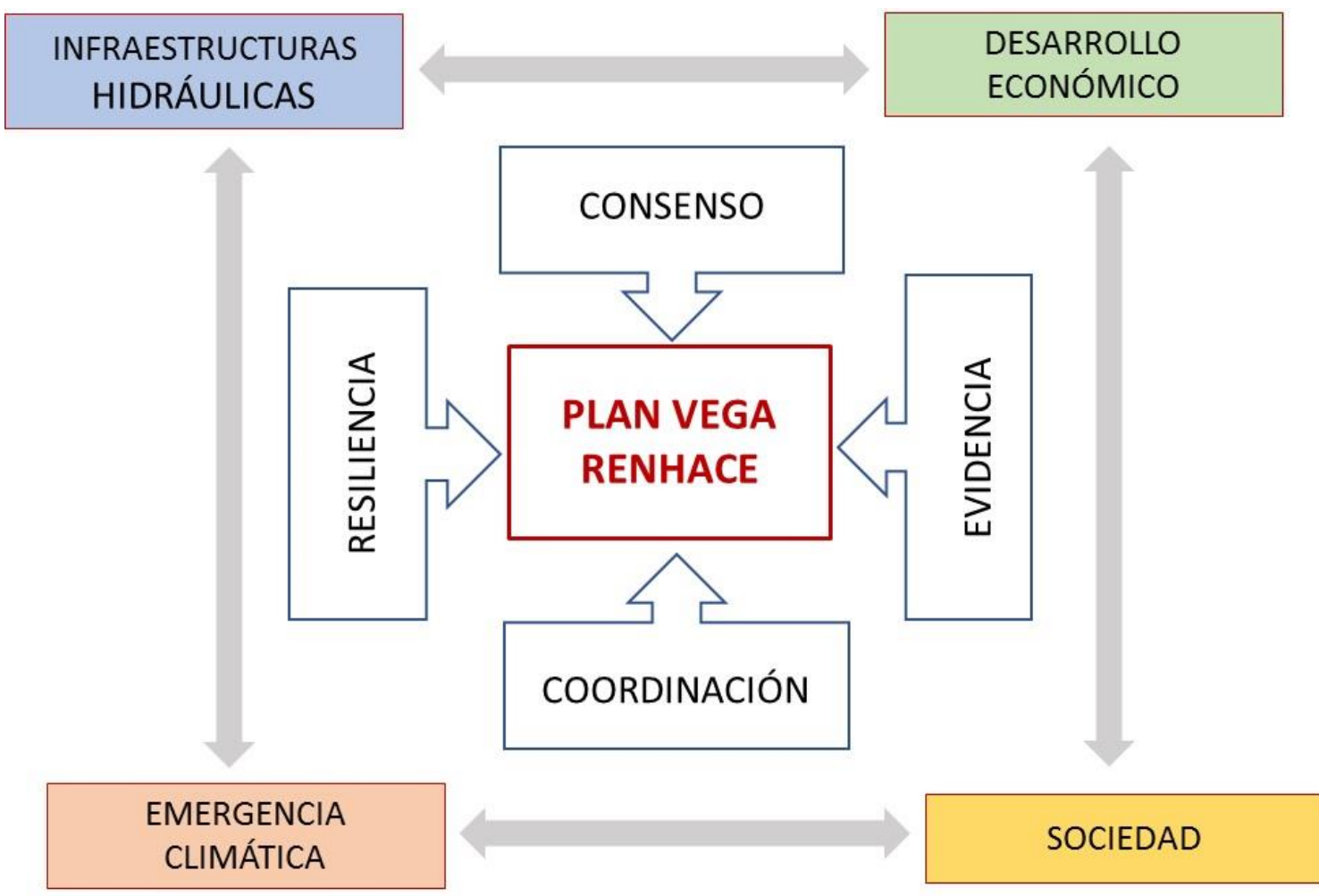

Fuente: elaboración propia.

El Plan Vega Rehace se organiza a partir de cuatro ejes principales de actuación:

- Eje 1. Mejora de las infraestructuras hidráulicas: se plantean actuaciones en el cauce del río Segura y en los cauces problemáticos de la comarca, saneamiento y depuración de aguas, aprovechamiento del agua ante extremos climáticos (inundaciones y sequía) y permeabilidad de las infraestructuras.

- Eje 2. Emergencia climática: se persigue la excelencia en la prevención y gestión de las emergencias y capacidad de reaccionar ante impactos esperables, siendo prioritario la mejora de los sistemas de prevención y alertas, y de los protocolos de actuación.

- Eje 3. Desarrollo económico: se pretende impulsar un ecosistema resiliente que favorezca el desarrollo económico regenerativo, con especial prioridad en materia de agricultura, turismo, comercio e industria, cultura y patrimonio y tecnología.

- Eje 4. Sociedad: actuaciones dirigidas a dar una mayor protección a los colectivos vulnerables, especialmente en materia de vivienda, así como a colaborar a la toma de conciencia de la ciudadanía sobre la realidad del territorio y su relación con un entorno en riesgo por el cambio climático.

De la fase de participación ciudadana surgen ochenta propuestas de actuación para hacer más resiliente el territorio de la Vega Baja del Segura, de las cuales se priorizan veintiocho organizadas en los ejes principales señalados (Tabla1). 
Tabla 1. Actuaciones prioritarias del Plan Vega Renhace (2020)

\begin{tabular}{|c|c|c|}
\hline EJE & MEDIDA & ACTUACION \\
\hline \multirow{10}{*}{ 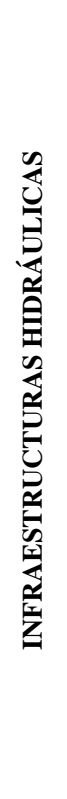 } & \multirow{2}{*}{$\begin{array}{l}\text { Permeabilización de } \\
\text { infraestructuras viarias }\end{array}$} & $\begin{array}{l}\text { ACTUACIÓN } 1 \text { Actuaciones de permeabilización de infraestructuras viarias y Corredor } \\
\text { hidráulico verde en torno al cauce del Segura }\end{array}$ \\
\hline & & $\begin{array}{l}\text { ACTUACIÓN 2. Actuación urgente en la N-332 en la desembocadura del río Segura: } \\
\text { permeabilización del tramo comprendido entre La Marina y Guardamar del Segura }\end{array}$ \\
\hline & \multirow{3}{*}{$\begin{array}{l}\text { Plan integral de limpieza y } \\
\text { mantenimiento del cauce del rio } \\
\text { Segura }\end{array}$} & ACTUACIÓN 3. Plan de limpieza integral del río Segura \\
\hline & & $\begin{array}{l}\text { ACTUACIÓN 4. Acuerdo entre la Confederación Hidrográfica del Segura y la Federación } \\
\text { Valenciana de Municipios y Provincias para la realización de actuaciones de limpieza en } \\
\text { cauces ubicados en zona urbana }\end{array}$ \\
\hline & & $\begin{array}{l}\text { ACTUACIÓN 5. Inversión en la reparación del mecanismo automático de la pantalla del } \\
\text { rio Segura y proyecto piloto de financiación de la limpieza }\end{array}$ \\
\hline & $\begin{array}{l}\text { Plan de infraestructuras hidráulicas } \\
\text { para la reducción de la peligrosidad } \\
\text { ante las inundaciones }\end{array}$ & $\begin{array}{l}\text { ACTUACIÓN 6. Convenio de la CHS con la Universitat Politècnica de València } \\
\text { (Departamento de Hidráulica) para realizar un estudio de inundabilidad de la cuenca }\end{array}$ \\
\hline & \multirow{2}{*}{$\begin{array}{l}\text { Actuaciones urbanas sostenibles } \\
\text { frente a inundaciones }\end{array}$} & ACTUACIÓN 7. Inversión en sistemas de drenaje sostenible \\
\hline & & ACTUACIÓN 8. Creación de "Islas Polder" en núcleos urbanos de riesgo \\
\hline & \multirow{2}{*}{$\begin{array}{l}\text { Garantizar el suministro de agua } \\
\text { para luchar contra la sequía }\end{array}$} & $\begin{array}{l}\text { ACTUACIÓN 9. Mantenimiento del actual esquema de dotaciones hídricas para } \\
\text { abastecimiento de las demandas agrarias, industriales y urbano- turísticas) de la comarca }\end{array}$ \\
\hline & & $\begin{array}{l}\text { ACTUACIÓN 10. Inversión en la mejora de la depuración de aguas residuales y su } \\
\text { reutilización para la agricultura y creación de un proyecto europeo para situar la conversión } \\
\text { de todas las depuradoras de la Comunitat Valenciana en uso terciario. }\end{array}$ \\
\hline \multirow{6}{*}{ 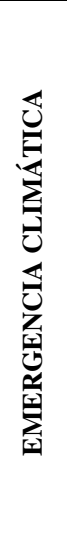 } & $\begin{array}{l}\text { Creación de un Centro de } \\
\text { Investigación de rango europeo en } \\
\text { Extremos, Emergencias y } \\
\text { Tecnologías del Agua }\end{array}$ & $\begin{array}{l}\text { ACTUACIÓN 11. Creación de un Centro de Investigación de rango europeo en Extremos, } \\
\text { Emergencias y Tecnologías del Agua }\end{array}$ \\
\hline & $\begin{array}{l}\text { Plan de emergencia comarcal y } \\
\text { planes municipales frente a las } \\
\text { inundaciones y el riesgo sísmico }\end{array}$ & $\begin{array}{l}\text { ACTUACIÓN 12. Implementación de planes de emergencias para todos los municipios de } \\
\text { la comarca con el empleo de técnicos superiores en emergencias para su elaboración }\end{array}$ \\
\hline & \multirow{3}{*}{$\begin{array}{l}\text { Desarrollo de una aplicación para } \\
\text { móviles (App) de alerta ante el } \\
\text { riesgo de inundaciones dirigida a la } \\
\text { ciudadanía }\end{array}$} & ACTUACIÓN 13. Creación de una app de Emergencias GVA \\
\hline & & $\begin{array}{l}\text { ACTUACIÓN 14. Firma de un acuerdo de Emergencias GVA con la Universidad de } \\
\text { Alicante para crear una biblioteca de mensajes de riesgo de inundaciones en la Vega Baja }\end{array}$ \\
\hline & & $\begin{array}{l}\text { ACTUACIÓN 15. Acuerdo Emergencias GVA y Hidraqua para el uso de una plataforma } \\
\text { de big data para la gestión de los embalses y las inundaciones }\end{array}$ \\
\hline & $\begin{array}{l}\text { Educación sobre el riesgo de } \\
\text { inundación para ciudadanía }\end{array}$ & $\begin{array}{l}\text { ACTUACIÓN 16. Plan de concienciación, educación e información ambiental sobre el } \\
\text { riesgo de inundación y sísmico para la ciudadanía y gestores públicos }\end{array}$ \\
\hline \multirow{9}{*}{ 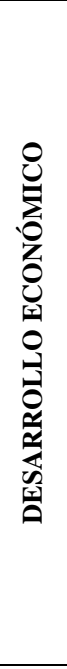 } & $\begin{array}{l}\text { Solución para la CV-95 y movilidad } \\
\text { sostenible de la comarca }\end{array}$ & $\begin{array}{l}\text { ACTUACIÓN } 17 \text {. Análisis de la movilidad motorizada y necesidad de actuaciones en la } \\
\text { red viaria de la comarca de la Vega Baja }\end{array}$ \\
\hline & Impulso polígonos industriales & $\begin{array}{l}\text { ACTUACIÓN 18. Estudio de planeamiento de la estación intermodal de la Vega Baja en } \\
\text { San Isidro, Alicante" }\end{array}$ \\
\hline & \multirow{2}{*}{ Vega Baja parque cultural } & ACTUACIÓN 19. Proyecto Parque Cultural \\
\hline & & ACTUACIÓN 20. Gestión inteligente del patrimonio cultural \\
\hline & \multirow[b]{2}{*}{ Impulso al turismo en la comarca } & ACTUACIÓN 21. Plan de dinamización y gobernanza turística dela Vega Baja \\
\hline & & $\begin{array}{l}\text { ACTUACIÓN 22. Impulso del turismo residencial en la comarca desde la perspectiva de la } \\
\text { sostenibilidad, enmarcando su crecimiento y desarrollo en la Agenda Urbana } 2030 \text { y los } \\
\text { Objetivos de Desarrollo Sostenible }\end{array}$ \\
\hline & $\begin{array}{l}\text { Diversificación de la economía a } \\
\text { través del impulso de sectores } \\
\text { tecnológicos }\end{array}$ & ACTUACIÓN .23. Puesta en marcha de un Centro de Economía Creativa y Digital \\
\hline & \multirow{2}{*}{$\begin{array}{l}\text { Impulso al sector agroalimentario y } \\
\text { mejora de los procesos agrícolas } \\
\text { mediante el uso de las nuevas } \\
\text { tecnologías }\end{array}$} & $\begin{array}{l}\text { ACTUACIÓN 24. Creación de un Centro de Investigación Agroalimentaria en el Campus } \\
\text { de Orihuela }\end{array}$ \\
\hline & & ACTUACIÓN 25. Inteligencia artificial aplicada a la agricultura \\
\hline \multirow{3}{*}{ 东 } & Mejora de la red transporte público & ACTUACIÓN 26. Plan de Movilidad de la Comarca de la Vega Baja \\
\hline & $\begin{array}{l}\text { Planes de adaptación a las viviendas } \\
\text { existentes en zonas inundables y su } \\
\text { financiación }\end{array}$ & $\begin{array}{l}\text { ACTUACIÓN 27. Guía virtual para la reducción de la vulnerabilidad de los edificios frente } \\
\text { a las inundaciones para impulsar un modelo de vivienda adaptado al entorno y al grado de } \\
\text { riesgo y peligrosidad }\end{array}$ \\
\hline & $\begin{array}{l}\text { Plan de Acción Territorial de la } \\
\text { Vega Baja }\end{array}$ & ACTUACIÓN 28. Plan de Acción Territorial de la Vega Baja \\
\hline
\end{tabular}

Fuente: Plan Vega Renhace. Generalitat Valenciana (2020). 
Como se puede comprobar, el $90 \%$ de las actuaciones propuestas en este plan estratégico de ámbito comarcal, tienen relación con la ordenación territorial y la planificación de futuros usos económicos, de equipamiento o infraestructura en el espacio de aplicación. De modo especial, hay la ciudadanía de la comarca señala la necesidad de un Plan de Acción Territorial que oriente la ordenación de este espacio geográfico bajo los principios de la sostenibilidad y la adaptación a los efectos del cambio climático.

A modo de reflexión final, junto a la necesidad de acuerdo entre las administraciones, el Plan Vega Renhace tiene una dificultad añadida para su desarrollo y es su carácter de plan estratégico, no normativo. De manera que depende de la voluntad política, en cada momento, para la puesta en marcha de las actuaciones previstas. Es, por tanto, un reto para la administración regional que debe actuar como órgano de coordinación entre administraciones y entidades. Y todo ello para demostrar la validez de la planificación estratégica como herramienta eficaz de ordenación de actuaciones y usos en el territorio.

\subsection{La oportunidad de la Ley Valenciana de Cambio Climático}

La ley de Cambio Climático y Transición Ecológica, presentada como propuesta, en la primavera de $2020^{3}$, supone un avance en la consideración política del calentamiento climático actual en el territorio de la Comunidad Valenciana. Se trata de un texto que aborda de forma integral las políticas y actuaciones administrativas para la reducción de los efectos del cambio climático, esto es, tanto las acciones de mitigación (energía) como de adaptación (planificación territorial, diseño urbano, educación). En relación con la ordenación del territorio, el texto legal contiene unas indicaciones relevantes que conviene analizar:

a) Incorporación de la perspectiva climática en los instrumentos de planificación.

b) Elaboración de planes de adaptación en la escala local.

c) Implantación de instalaciones energéticas de carácter comunitario.

d) Medidas de adaptación en zonas costeras.

La propuesta de ley señala que en todos los instrumentos de ordenación territorial que se desarrollen a partir de su aprobación deberá incorporarse la perspectiva climática, materializada en tres aspectos: a) análisis de su impacto sobre las emisiones de gases de efecto invernadero directas e inducidas, así como medidas destinadas a minimizarlas o compensarlas en caso de que no se puedan evitar; b) análisis de la vulnerabilidad actual y prevista ante los efectos del cambio climático y medidas destinadas a reducirla; y, c) una evaluación de las necesidades energéticas de su ámbito de actuación y la determinación de las medidas necesarias para minimizarlas y para garantizar la generación de energía de origen renovable. Asimismo, se señala la obligación de que los nuevos desarrollos urbanísticos reserven áreas de suelo para la generación de energía renovable en una extensión suficiente para que se garanticen las necesidades energéticas de esos nuevos desarrollos.

\footnotetext{
${ }^{3}$ El documento de Anteproyecto de esta ley puede consultarse en: https://www.coitavc.org/borrador-de-laley-valenciana-de-cambio-climatico-y-transicion-ecologica-com-1-50-0-5808/ (Consultado: octubre 2020).
} 
Por su parte, la evaluación ambiental de planes y programas deberá tener en cuenta el cambio climático como criterio importante a desarrollar en los informes que acompañan este proceso administrativo.

Tal vez, el procedimiento que va a tener un impacto mayor en la escala local es la obligación, incluida en el artículo 18 del proyecto de Ley, de elaboración por parte de todos los municipios valencianos de Planes de cambio climático. En dichos planes se debe incluir un análisis y la evaluación de emisiones de gases de efecto invernadero, la identificación y caracterización de los elementos vulnerables, la relación de objetivos y las estrategias para la mitigación y la adaptación al cambio climático, que incluya las posibles modificaciones adecuadas del planeamiento urbanístico y las ordenanzas municipales, acciones de sensibilización y formación y, por último, las reglas para la evaluación y seguimiento del Plan.

Como refuerzo de esta medida, se dedica un apartado especial a la adaptación al cambio climático en zonas costeras, por los efectos importantes previstos por la modelización climática en dichos ámbitos en el litoral mediterráneo. Para ello se señala que la identificación de los espacios, sectores y ámbitos más expuestos a riesgos, las administraciones competentes, en sintonía con el Programa de adaptación al cambio climático establecido en el artículo 12, elaboraran sus planes de adaptación para la reducción de dichos riesgos e implementaran las medidas identificadas. Para ello se realizará e incorporará la evaluación económica de las medidas y soluciones técnicas a adoptar, priorizando las mismas en base al criterio coste-beneficio, donde el beneficio tendrá en cuenta tanto a la población, como los bienes materiales y el patrimonio natural afectado frente al coste económico de la adopción de las medidas. Se trata de la regulación de un problema importante, la gestión de la franja costera en la Comunidad Valenciana, que en los últimos años ha padecido los efectos de temporales importantes (enero de 2017, enero 2020), con daños económicos cuantiosos en algunos lugares. A la vista de las ayudas económicas cuantiosas que supone la reparación daños y reconstrucción de la franja costera tras el desarrollo de un temporal marítimo, se ha abierto el debate de la necesidad de reconsiderar la ocupación existente en algunos municipios en primera línea de costa, a los que la vigente ley de costas (2013) ha ampliado el período concesional, en aquellas implantaciones existentes en dominio público marítimo terrestre.

En definitiva, estos artículos del proyecto de ley, son una apuesta necesaria para ir adaptando la planificación urbana a los principios de mitigación y adaptación al cambio climático. Para ello el texto legal incluye varios artículos dedicados a la promoción de la movilidad sostenible o a la regulación de parámetros para la instalación de puntos de recarga eléctrica para los vehículos en calzadas y aparcamientos. Para su elaboración se contempla la creación de un instrumento financiero de la comunidad autónoma para su uso por las entidades locales.

Por su parte, la normativa señala que se impulsará la reducción de emisiones tanto en el proceso de construcción de edificaciones como en su diseño que debe ser eficiente. El artículo 33 señala que "las nuevas edificaciones que se construyan deberán ser edificios de consumo energético casi nulo", lo que va a suponer un cambio notable en los procesos edificatorios, cuando se apruebe la ley. Todo ello se tendrá en cuenta para el cálculo de la huella regional de carbono.

La ley hace una apuesta por la necesidad de implantar un cambio en el modelo urbanístico que deberá priorizar la rehabilitación del parque de vivienda, frente a los nuevos desarrollos, y la construcción de edificios de consumo energético casi nulo (art. 37). Explícitamente se señala que: "la adaptación de la normativa urbanística y ambiental para 
que tanto las figuras de nuevos planeamientos urbanísticos, sus modificaciones y revisiones como el planeamiento territorial incorporen un análisis cuantitativo y una valoración descriptiva del impacto sobre las emisiones de gases de efecto invernadero y los impactos del cambio climático sobre el nuevo planeamiento, así como medidas para mitigarlo y adaptarse a él”.

Un apartado que puede generar desacuerdo en la escala local es la obligación de reserva de espacio para la implantación de instalaciones de energía renovable que se adecuarán a las normas territoriales y urbanísticas y se les reconocerá el uso compatible con los usos propios del suelo no urbanizable común. El Consell establecerá zonas de desarrollo prioritario para la implantación de este tipo de instalaciones definidas como aquellas unidades territoriales, delimitadas mediante instrumentos de planeamiento urbanístico y territorial de ámbito supramunicipal en cualquier tipo de suelo, donde las instalaciones de energía renovable tendrán la consideración de uso admitido a efectos de la legislación territorial y urbanística. La condición de uso admitido será de aplicación directa y el planeamiento urbanístico lo deberá respetar.

En otoño de 2020 el texto ha entrado en trámite parlamentario (Cortes Valencianas) para su aprobación. Es importante que, con las modificaciones que pueda experimentar en dicho proceso, quede aprobado y comience su desarrollo en los próximos años que van a resultar decisivos para la transformación territorial y económica que debe llevarse a cabo en el territorio europeo para cumplir los objetivos de "descarbonización" de la economía fijados con horizonte 2030 y 2050. Esta norma, como la tramitada para el ámbito español, persiguen la regulación de este proceso orientado a la mitigación y adaptación ante los efectos del cambio climático. La ordenación del territorio es un proceso eficaz en el conjunto de actuaciones necesarias, si se entiende desde los principios de la sostenibilidad.

\section{DISCUSIÓN Y CONCLUSIONES}

El cambio climático es, y va a seguir siendo, un eje prioritario de políticas públicas y acciones privadas en territorios de alta exposición a sus efectos, como son las regiones del litoral mediterráneo español. Del conjunto de actuaciones que pueden desarrollarse para reducir sus efectos (pérdida de confort térmico, mayor irregularidad de las precipitaciones, frecuencia elevada de eventos extremos), la ordenación del territorio es un procedimiento especialmente eficaz para la mitigación y adaptación al cambio climático.

Progresivamente los procesos de planificación territorial van incorporando el cambio climático y los extremos atmosféricos asociados como elemento importante de la infraestructura verde de un espacio geográfico, a diversa escala. Los avances en los análisis y cartografía de riesgo, así como en la modelización climática permite incluir estos elementos en la ordenación territorial. La escala local es fundamental en este proceso, si bien las orientaciones de planificación desde las escalas superiores (subregional y regional) deben dirigir los contenidos y procedimientos a desarrollar en los informes que acompañan un proceso de ordenación territorial.

La Comunidad Valenciana ha desarrollado, en los últimos años, planes normativos y estratégicos, y normativa que han incorporado la reducción del cambio climático y de sus extremos atmosféricos y ambientales asociados, como principio importante en el establecimiento de actuaciones. El PATIVEL, el Plan Vega Renhace y la Ley Valenciana 
de Cambio Climático son documentos oficiales que pueden presentarse como ejemplo de buenas prácticas en esta cuestión. Se trata de planes y normativas recientes, aprobadas en la última década, tras el proceso intenso de transformación, de artificialización, del territorio que experimentó la Comunidad Valenciana durante los años del boom inmobiliario, y que pretenden orientar futuras actuaciones en ámbitos sensibles (litoral, área inundable) hacia los principios de la sostenibilidad territorial y ambiental en las escalas administrativas básicas de la planificación (regional y local). Y que establecen ley de cambio climático- determinaciones jurídicas de obligado cumplimiento en la planificación urbana para adaptar el desarrollo futuro de nuevos usos en el territorio a los objetivos de mitigación y adaptación al cambio climático.

La aplicación y gestión de sus determinaciones y actuaciones previstas se presenta como un reto para la consolidación de una apuesta necesaria por la sostenibilidad territorial que debe ser el principio rector de planes y programas territoriales en las próximas décadas, en el marco del cumplimiento de los objetivos de desarrollo sostenible (ODS) y de la estrategia europea de descarbonización de la economía con horizonte 2050. La consideración del medio natural, en su comportamiento normal y extremo, es un principio de actuación ética irrenunciable de las sociedades que pretenden vivir en armonía con su territorio, desarrollando sus potencialidades, pero sin exceder sus límites y anticipándose a las incertidumbres de sus rasgos climáticos.

\section{AGRADECIMIENTOS}

El autor quiere agradecer a los promotores de este número especial de la revista TERRA por la oportunidad otorgada para participar en él. Este articulo está dedicado a Joan Noguera, geógrafo de raza y excelente persona, con el que he podido compartir excelentes ratos de academia y amistad. Sirva este texto de reconocimiento a sus aportaciones novedosas e inteligentes a la gestión territorial y desarrollo local del territorio valenciano.

\section{REFERENCIAS}

Agencia Estatal de Meteorología (AEMET) (2019). Proyecciones climática para el siglo XXI en España. Agencia Estatal de Meteorología, Ministerio para la Transición Ecológica y el Reto Demográfico. Recuperado de http://www.aemet.es/es/serviciosclimaticos/cambio_climat.

Ariño, A. (Dir.) y García, P. (coord.) (2018). La sociedad valenciana en transformación (1975-2025). Publicaciones de la Universitat de València, Valencia.

Barragán, J. M. (2014). Política, Gestión y Litoral. Una Nueva Visión de la Gestión Integrada de Áreas Litorales. Tebar Flores. Libros de la Unesco.

Benedict, M. A., y McMahon, E. T. (2002). Green infrastructure: smart conservation for the 21st century. Renewable Resources Journal, (20), 12-17. Recuperado de: http://www.greeninfrastructure.net/sites/greeninfrastructure.net/files/GI_RR.pdf.

Breuste, J., Artmann, M., Li, J., y Xie, M. (2015). Introduction (special Issue on Green Infrastructure for Urban Sustainability). Journal of Urban Planning and Development, 141(3). Recuperado de: https://ascelibrary.org/doi/full/10.1061/\%28ASCE\%29UP.1943-5444.0000291 
Burriel, E. L. (2008). La década prodigiosa del urbanismo español (1997-2006). Scripta Nova. Revista Electrónica de Geografía y Ciencias Sociales, XII (270, 64). Recuperado de http://www.ub.es/geocrit/sn/sn-270/sn-270-64.htm

Burriel, E. L. (2009). La planificación territorial en la Comunidad Valenciana (19862009). Scripta Nova. Revista Electrónica de Geografía y Ciencias sociales, XIII (306). Recuperado de: http://www.ub.es/geocrit/sn/sn-306.htm

Capdepón, M. (2016). Conflictos ambientales derivados de la urbanización turísticoresidencial. Un caso aplicado al litoral alicantino. Boletín de la Asociación de Geógrafos Españoles, (71), 31-57, https://doi.org/10.21138/bage.2273

Comisión Europea (2013). Infraestrutura verde: mejora del capital natural de Europa. Comunicación de la Comisión al Parlamento Europeo, al Consejo, al Comité Económico y Social Europeo y al Comité de las Regiones. Bruselas, 6.5.2013. COM (2013) 249 final. Recuperado de: http://ec.europa.eu/environment/nature/ecosystems/strategy/index_en.htm

Comisión Europea (2014). Construir una infraestructura verde para Europa. Belgium.

Comisión Europea (2016). Supporting the Implementation of Green Infrastructure. Final Report. Rotterdam.

Comité de Desarrollo Territorial (1999). Estrategia Territorial Europea. Hacia un desarrollo equilibrado y sostenible del territorio de la UE. Comisión Europea, Luxemburgo. Recuperado de: http://ec.europa.eu/regional_policy/sources/docoffic/official/reports/pdf/sum_es.p df

Consellería de Vivienda, Obras Públicas y Vertebración del Territorio (2018). Plan de Acción Territorial de la Infraestructura Verde del Litoral. Recuperado de: http://www.habitatge.gva.es/es/web/planificacion-territorial-e-infraestructuraverde/plan-de-accion-territorial-de-la-infraestructura-verde-del-litoral

Cramer, W., Guiot, J., Fader, M., Garrabou, J., Gattuso, J. P., Iglesias, A., Lange, M. A., Lionello, P., Llasat, M. C., Paz, S., Peñuelas, J., Snoussi, M., Toreti, A., Tsimplis, M. N., y Xoplaki, E. (2018). Climate change and interconnected risks to sustainable development in the Mediterranean. Nature Climate Change (8), 972-980, doi: $10.1038 /$ s41558-018-0299-2

Elorrieta, B., Olcina, J., y Sánchez, D. (2016). La sostenibilidad en la planificación territorial de escala regional. Cuadernos Geográficos, 55 (1), 149-175.

EPA (2017). Green Infraestructure in parks. US-EPA. Officc of water. Recuperado de: https://www.epa.gov/sites/production/files/2017-

05/documents/gi_parksplaybook_2017-05-01_508.pdf

ESPON (2014). European Land Use Patterns. Applied Research. Final Report. European Union. ESPON Coordination Unit, Luxembourg. Disponible en: https://www.espon.eu/programme/projects/espon-2013/applied-research/eu-lupaeuropean-land-use-patterns

Farinós, J. (2011). La gestión integrada de zonas costeras, ¿Algo más que una ordenación del litoral revisada?. Publicaciones de la Universitat de València, Valencia.

Farinós, J. (2012). De la Evaluación Ambiental Estratégica a la Evaluación de Impacto Territorial: reflexiones acerca de la tarea de evaluación. Publicaciones de la Universitat de València. 
Gaja, F. (2008). El "tsunami urbanizador" en el litoral mediterráneo. El ciclo de hiperproducción inmobiliaria 1996-2006. Scripta Nova. Revista electrónica de Geografía y Ciencias Sociales, XII (270, 66). Recuperado de: http://www.ub.es/geocrit/sn/sn-270/sn-270-66.htm

Generalitat Valenciana (2018). Plan de Acción Territorial de Infraestructura Verde del Litoral de la Comunidad Valenciana (PATIVEL). Valencia, Consellería de Política Territorial, Obras Públicas y Movilidad. Recuperado de: http://politicaterritorial.gva.es/es/web/planificacion-territorial-e-infraestructuraverde/plan-de-accion-territorial-de-la-infraestructura-verde-del-litoral

Generalitat Valenciana (2019). Objetivos de Calidad e Instrucciones Técnicas para la ordenación y gestión de los Paisajes de Relevancia Regional de la Comunitat Valenciana. Consellería de Política Territorial, Obras Públicas y Movilidad, Dirección General de Política Territorial y Paisaje, Valencia. Recuperado de: http://politicaterritorial.gva.es/es/web/planificacion-territorial-e-infraestructuraverde/paisatges-de-rellevancia-regional

Generalitat Valenciana (2020). Plan Vega Rehace. Una estrategia integral para la resiliencia de la comarca de la Vega Baja del Segura. Valencia, Dirección General de Análisis y Políticas Públicas. Recuperado de: http://www.presidencia.gva.es/es/web/vega-renhace

IPCC (Intergovernmental Panel on Climate Change) (2014). Climate Change 2013 and Climate Change 2014. Recuperado de: http://www.ipcc.ch/

IPCC (Intergovernmental Panel on Climate Change) (2018). Global Warning of $1,5^{\circ} \mathrm{C}$. Special Report. Recuperado de: https://www.ipcc.ch/sr15/

Katuric, I. (2021). The future of Green Infraestructure in the EU: Opportunities and Guidelines. Cuadernos FUNDICOT (2), 79-96.

Lafortezza, R., Davies, C., Sanesi, G., y Konijnendijk Van Den Bosch, C. (2013). Green Infrastructure as a tool to support spatial planning in European urban regions. iForest - Biogeosciences and Forestry, (6). DOI.10.3832/ifor0723-006.

Losada, I., Izaguirre, C., y Diaz, P. (2014). Cambio climático en la costa española. Oficina Española de Cambio Climático, Ministerio de Agricultura, Alimentación y Medio Ambiente. Madrid. Recuperado de: https://www.adaptecca.es/sites/default/files/documentos/2014_informe_c3e_final _cambio_climatico_en_la_costa_espanola.pdf.

Meerow, S., y Newell, J. P. (2017). Spatial planning for multifunctional green infrastructure: Growing resilience in Detroit. Landscape and Urban Planning, (159), 62-75.

Mell, I. C. (2008). Green Infrstructure: concepts and planning. FORUM Ejournal (8), 6980 . https://research.ncl.ac.uk/forum/v8i1/green\%20infrastructure.pdf

Nazyddah Mat Nazir, N., Othman, N., y Nawawi, A. H. (2014). Green Infrastructure and its Roles in Enhancing Quality of Life. Procedia - Social and Behavioral Sciences, (153), 384-394.

Olcina, J. (2012). Globalisation and Sustainability: Threats to the environment in a globalised world. The point of view of Spanish geography. New trends in the XXI 
century Spanish Geography. Madrid. Comité Español de la Unión Geográfica Internacional, 374-392.

Olcina, J. (2013). Experiences in adapting to Climate Change and Climate Risk in Spain. In P. Schmidt-Thome (ed.), Climate Change Adaptation in practice: from strategy development to implementation (pp. 253-268). Wiley-Blackwell,

Olcina, J. (2020). Clima, cambio climático y riesgos climáticos en el litoral mediterráneo. Oportunidades para la geografía. Documents de Analisi Geografica, 66 (1), 159182.

Olcina, J., y Díez-Herrero, A. (2016). Cartografía de inundaciones en España. Estudios Geográficos, LXXVIII (282), 283-315.

Padilla, A., Prieto, A., Marco, J. A., Giménez, P., y Sánchez, Á. (2019). El papel del inventario ambiental exhaustivo en el proceso de la configuración definitiva de la Infraestructura Verde del litoral sur de la Comunitat Valenciana. Boletín de la Asociación de Geógrafos Españoles, $82 \quad$ (2805), 1-37. http://dx.doi.org/10.21138/bage.2805

Pauleit, S., Hansen, R., Lorance, E., Zölch, T., Andersson, E., Luz, A. C., Szaraz, L., Tosics, I., y Vierikko, K. (2017). Urban Landscapes and Green Infrastructure. Environmental Sciences, Oxford Researchs Encyclopedias. Recuperado de: http://environmentalscience.oxfordre.com/view/10.1093/acrefore/9780199389414 .001.0001/acrefore-9780199389414-e-23.

Romero, J. (2011). Construcción residencial y gobierno del territorio en España. De la burbuja especulativa a la recesión. Causas y consecuencias. Cuadernos Geográficos de Granada, (47), 17-46.

Rullan, O. (2012). Urbanismo expansivo en el Estado español: de la utopía a la realidad. En V. Gozálvez, y J. A. Marco (eds.), Geografía. Retos ambientales y territoriales (pp. 165-209). Universidad de Alicante. Recuperado de: http://citywiki.ugr.es/w/images/6/6f/2012_ORullan_AGE_Alacant.pdf

Sánchez, J. V. (2015). Políticas de gestión del territorio, ambientales y del paisaje. En J. Romero, y A. Boix (eds.), Democracia desde abajo. Nueva agenda para el gobierno local (pp. 153-180). Publicaciones de la Universitat de València.

Torres, F. J. (2009). La ocupación del dominio público marítimo-terrestre en España. Investigaciones Geográficas (50), 63-91. Recuperado de: https://www.investigacionesgeograficas.com/article/view/2009-n50-la-ocupaciondel-dominio-publico-maritimo-terrestre-en-espana/pdf

Torres, F. J. (2010). Cuarenta años de leyes de costas en España (1969-2009). Investigaciones geográficas, (52), 167-200. Recuperado de: https://www.investigacionesgeograficas.com/article/view/2010-n52-cuarentaanos-de-leyes-de-costas-en-espana-1969-2009/pdf

Tudela, A., y Delgado, A. (2018). Playa Burbuja, un viaje al reino de los señores del ladrillo. Datadista.

Vera, J. F., y Espejo, C. (2006). El papel de los instrumentos de planificación en las dinámicas productivas y territoriales: las Directrices y Plan de Ordenación del Litoral de la Región de Murcia. En J. Romero, y J. Farinós (eds), Gobernanza territorial en España. (pp. 61-79). Publicacións de la Universitat de València. 
Vera, J .F., y Olcina, J. (2017). Análisis de la coherencia metodológica y de los datos utilizados en la memoria justificativa del PATIVEL. Conselleria de Vivienda, Obras Públicas y Vertebración del Territorio de la Generalitat Valenciana, Universidad de Alicante (inédito).

Vera, J. F., Olcina, J., y Sainz-Pardo, A. (2019). La incorporación de la infraestructura verde en la ordenación territorial. El plan de acción territorial de la infraestructura verde del litoral de la Comunidad Valenciana, PATIVEL. Ciudad y Territorio. Estudios Territoriales, LI (200), 467-490.

VV.AA. (2013). Manifiesto por la preservación y gestión de los espacios costeros. Asociación de Geógrafos Españoles. Madrid. Recuperado de: http://www.agegeografia.es/site/wp-content/uploads/2015/01/costas_version_final.pdf

Wang, J., y Banzhaf, E. (2018). Towards a better understanding of Green Infrastructure: A critical review. Ecological Indicators, (85), 758-772.

Weber, T., Sloan, A., y Wolf, J. (2006). Maryland's Green Infrastructure assessment: development of a comprehensive approach to land conservation. Landscape and Urban Planning, 77 (1-2), 94-110. DOI: 10.1016/j.landurbplan.2005.02.002. 


\section{EXTENDED ABSTRACT ${ }^{4}$}

Current climate change process is scientific evidence with direct effects on atmospheric elements (temperature, rainfall, etc.), but with repercussions also on uses and economic activities implemented in geographical areas. Hence, the consideration of the global warming process that has been recorded in recent decades must be comprehensive, addressing policies and practices that affect the causes and effects expected in the modeling. Regional, subregional and local scales are decisive in the actions to be developed, as it is the area closest to the public and the one with greatest capacity to carry out actions with greatest impact on adaptation to climate change. This is so both due to the implementation of its own actions, as well as the application of actions derived from the application, at the municipal level, of the determinations of plans and higher-scale standards.

At present, the planning of the territory has challenges in the framework of sustainability and climate change, as a guiding principle of the actions to be planned in the environment: a) it must consider the resources and risks of the physical environment; b) it must incorporate the environmental regulations issued by the competent administrations; c) it must comply with the hierarchy of work scales that are fundamental in legal practice; and d) it must incorporate a continuous diagnosis phase based on the design of monitoring indicators for the continuous evaluation of the plans. And all this, under the principle of transparency and open information to society by competent administrations.

The incorporation of landscape, as a fundamental spatial planning criterion, and of green infrastructure, as a tool for territorial management, allow incorporating, among other aspects, climate change into the planning of the territory. To this finality, cartographies and models that can be used when defining the green infrastructure layers that establish the first delimitation between the geographical area to be protected and the geographical area than will be actionable.

The aspects that green infrastructure must specifically incorporate into urban and regional spatial planning to reduce the effects of climate change, are the following: a) increase in temperatures and loss of thermal comfort, the effects of which can be mitigated through urban design measures such as the increase in public parks, green spaces in homes (terraces and green facades): b) rise in sea level in coastal areas, the effects of which must be reduced with structural actions, in some cases, and with territorial planning (regulation of uses along the coastline, vacant coastlines). And c) changes in rainfall, with an increase in its intensity and irregularity, which makes it necessary to design large-capacity water drainage spaces, as well as water storage tanks of greater capacity than existing ones to guarantee supply of urban demands. All this must be based on the elaboration of rigorous behavior models of climatic or environmental elements (sea level) and that allow the periodic updating of the projections with a view to their application in territorial planning.

In Valencian Community (Spain), some actions, plans and regulations have been developed, which have climate change as the guiding principle for the achievement of sustainable territorial development. These are PATIVEL (Territorial Action Plan for Green Coastal Infrastructure), the Vega Renhace Plan and the Valencian Climate Change Law.

Along with the rest of the green infrastructure parameters contemplated in the Valencian Territorial Strategy (2011), Pativel has included in the definition of the green

\footnotetext{
${ }^{4}$ Traducción exclusiva de los autores / Authors' exclusive translation.
} 
infrastructure at the littoral areas, the influence of climate change in the coastal strip (sea level rise, flooding areas due to increased episodes of river flooding). In this last aspect, PATIVEL is novel at the state level. For this, it has considered the "Effects of climate change on the Spanish coast Report", of the Ministry of Ecological Transition, as well as other works on the Valencian littoral to estimate the evolution of the Valencian coast in a double sense: erosion due to littoral drift and the effects of surge storms.

For its part, the purpose of the Vega Renhace Plan is to turn the catastrophe into an occasion to promote a resilient environment that favors the economic and social regeneration of the Vega Baja. And, at the same time, promote a territorial development, respectful with the environment, that prepares for future episodes of storms, and that allows a greater structuring of the territory of the Vega Baja with the rest of the Valencian Community. The Vega Renhace Plan has been organized into four fundamental pillars: coordination, consensus, evidence and resilience. These pillars have acted as the backbone of the need to join efforts of various actors, public and private, to achieve great common objectives.

Finally, the Law on Climate Change and Ecological Transition, presented as a normative proposal in the spring of 2020, represents an advance in the political consideration of current climate warming in the territory of the Valencian Community. It is a text that comprehensively addresses policies and administrative actions to reduce the effects of climate change, that is, both mitigation actions (energy) and adaptation (territorial planning, urban design, education). The proposed law indicates that in all territorial planning instruments that are developed after its approval, the climate perspective must be incorporated. In short, numerous articles of the bill are a necessary bet to adapt urban planning to the principles of mitigation and adaptation to climate change.

In short, climate change is, and will continue to be, a priority axis for public policies and private actions in territories with high exposure to its effects, such as the regions of the Spanish Mediterranean coast. Of the set of actions that can be developed to reduce its effects (loss of thermal comfort, greater irregularity in rainfall, high frequency of extreme weather events), spatial planning is a particularly effective procedure for mitigating and adapting to climate change.

The application and management of its determinations and planned actions is presented as a challenge for the consolidation of a necessary commitment to territorial sustainability that should be the guiding principle of territorial plans and programs in the coming decades, within the framework of the fulfillment of the Sustainable Development Goals (SDG) and European Strategy of economy decarbonization (2050 horizon).

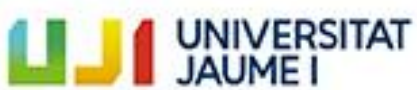

Institut Interuniversitari de Desenvolupament Local
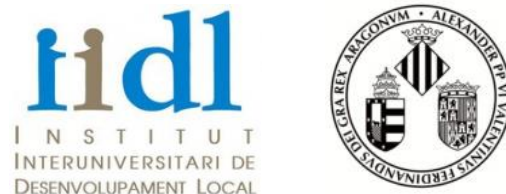

VNIVERSITAT (E) València 